\title{
论文
}

\section{热带西印度洋年代际增暖对2020年超强梅雨的 可能贡献}

郭媛媛 $^{1 \dagger}$, 张芮洁 ${ }^{1 \dagger}$, 温之平 ${ }^{1,2,3^{*}}$, 李俊苁 ${ }^{1}$, 张超 ${ }^{1}$, 周自江 ${ }^{4}$

1. 复旦大学大气与海洋科学系/大气科学研究院, 上海 200438 ;

2. 珠海复旦创新研究院海气系统监测与预测创新中心, 珠海 518057 ;

3. 江苏省气候变化协同创新中心, 南京 210023 ;

4. 国家气象信息中心, 北京 100081

†共同第一作者

* 通讯作者, E-mail: zpwen@fudan.edu.cn

收稿日期: 2020-11-18; 收修改稿日期: 2021-01-12; 接受日期: 2021-03-29; 网络版发表日期: 2021-06-03

国家重点研究发展计划项目(编号: 2016YFA0600601)和国家自然科学基金项目(批准号: 41905072、42030601、41875087)资助

摘要 2020年6 7月我国长江中下游地区遭受了超强持续性梅雨的侵袭, 其累积降水量打破了1961年以来的历史 记录. 通过分析1979 2020年长江流域梅雨期降水, 发现相比于7月而言, 6月长江流域梅雨呈现出更加显著的年代 际变化特征. 21 世纪初期以来, 热带西印度洋海温经历了明显的年代际增暖. 观测分析和模式试验均表明, 5 6月 热带西印度洋海温异常与6月长江流域降水存在显著的年代际相关. 热带西印度洋异常增暖可以有效调制并加强 西北太平洋反气旋, 其西北侧异常强的西南风将大量水汽输送至长江流域, 为超强梅雨的发生提供有利的大尺度 环流条件. 21 世纪初热带西印度洋海温异常由冷位相转为暖位相, 使 2020 年 5 月的海温异常高达 $0.7^{\circ} \mathrm{C}$, 约为 1.8 倍 标准差, 显著提高了2020年梅雨期内强降水过程的发生概率.

关键词超极梅雨, 西北太平洋反气旋, 海温异常

\section{1 引言}

梅雨是春末夏初东亚季风区特有的雨季, 它与我 国长江中下游地区的洪涝灾害联系密切，对当地的农 业生产、经济活动和人民生活等有重要影响. 因此, 研究梅雨的变化规律及其成因对社会经济生活具有重 要的指导意义. 2020年梅雨期内(6 7月), 我国长江流 域发生了历史罕见的持续性极端降雨事件(图1a和1b).
中国气象局的观测数据表明，2020年长江流域梅雨期 的累计降水量达到 $759.2 \mathrm{~mm}$, 约为气候平均态的 1.2 倍, 打破了1961年以来的历史记录. 2020年超强梅雨诱发 的洪涝灾害给我国带来了严重的经济损失 (http:// www.cma.gov.cn/2011wmhd/2011wzbft/2011wftzb/ 202008/t20200805_560160.html). 因此, 研究此次超强 梅雨的变化及成因, 对提高我国梅雨期强降水事件的 预报能力具有现实意义, 将为我国防灾减灾的政府决 
(a) 2020 年6 7月(NMIC)

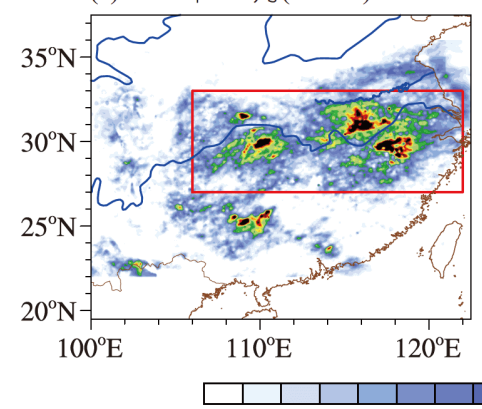

(b) 2020 年6 7月(CPC)

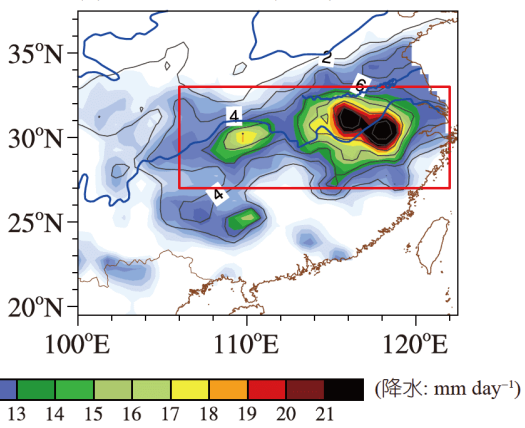

(c) 2020年6 7月(CPC)

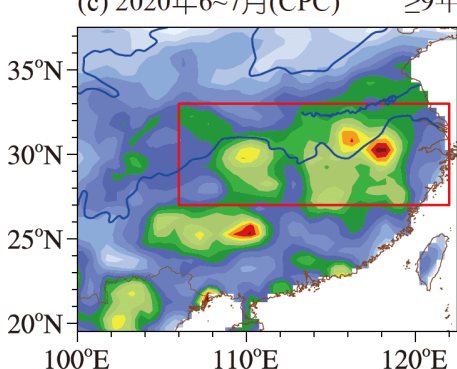

(d) 2020年6月(CPC)

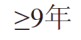

(e) 2020 年7月(CPC)

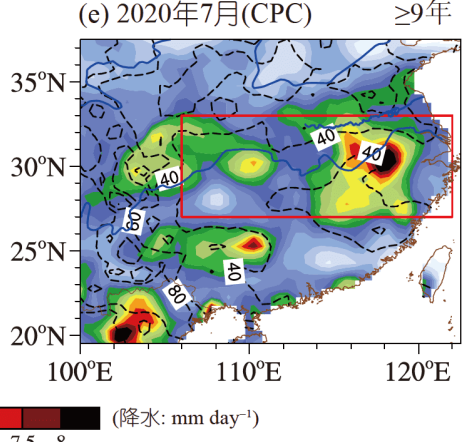

图 $1 \quad 2020$ 年6 7月长江流域降水空间分布

(a) 6 7月降水, 资料源自国家气象信息中心(NMIC)提供的融合降水资料; (b) 6 7月降水(填色)及其异常(等值线), 资料源自 CPC 降水资料; (c) 6 7月降水异常的年代际分量; (d) 6月降水异常年代际分量(填色)及方差贡献(等值线, 单位: \%); (e) 7月降水异常年代际分量(填色)及方差贡献 (等值线, 单位: \%). 红框代表长江流域, 空间范围为 $27^{\circ} \mathrm{N} \sim 33^{\circ} \mathrm{N}, 106^{\circ} \mathrm{E} \sim 122^{\circ} \mathrm{E}$

策提供科学依据和参考.

大量研究表明，梅雨存在多时间尺度振荡特征(杨 静和钱永甫, 2009; 梁萍和丁一汇, 2012; Ha等, 2016; 梁萍等, 2018; Ding等, 2020), 其在年代际或更长时间 尺度上表现为 $10 \sim 16 、 20 \sim 30$ 和 $60 \sim 80$ 年等振荡周期 (Ge等, 2008; Si等, 2009; 梁萍等, 2018; Sun等, 2019). 例如，梁萍等(2018)指出梅雨的年代际振荡周期为 12 16、准32及准64年; 魏风英和谢宇(2005)则认为梅 雨的主导周期为 20 和 $36 \sim 38$ 年. 由此可见，梅雨期降水 存在十分显著的年代际振荡特征，然而梅雨的年代际 分量是否对2020年超强梅雨的发生有重要贡献？这一 问题尚未明确.

梅雨是东亚夏季风(EASM)进程中的特有雨季, 其 年代际振荡与热带、中高纬地区的海表温度联系紧密 (Lau等, 2004; Ding等, 2010; Liu和Chang, 2012; Chen 等, 2013; Feng等, 2014; Zhu等, 2014; Ha等, 2016; Si和 Ding, 2016). 许多学者指出, 在20世纪60年代末期以后, 太平洋年代际振荡(PDO) (Zhang等，1997; Mantua等,
1997; Mantua和Hare, 2002)与长江流域夏季降水呈现 显著正相关, 即PDO位于暖(冷)位相时, 梅雨期降水异 常偏多(少)(Lau等，2004；Zhu等，2015；Si和Ding， 2016). 此外, 大西洋多年代际振荡(AMO) (Schlesinger 和Ramankutty，1994)也会显著调制我国东部梅雨期降 水, 当AMO位于暖(冷)位相时, 其异常海温会激发环北 半球大气遥相关, 从而导致长江流域降水异常偏少 (多), 黄淮流域降水异常偏多(少) (Si和Ding, 2016). 反 观2020年夏季, PDO位处冷位相而AMO位处暖位相 (图略)，二者共同作用将会导致2020年长江流域夏季 降水较往年偏少，但事实并非如此，这表明2020年超 强梅雨还受到其他影响因子的调控.

除PDO和AMO以外, 热带印度洋海表温度的异常 变化是影响我国长江流域旱涝的重要因子之一(Ding 等, 2010; Zhang等, 2017; Chen等, 2018; Xie和Wang, 2020), 西北太平洋反气旋(WNPAC) 是联系梅雨和热带 海温的关键系统(符淙斌和滕星林，1988; Zhang等, 1996; Chang等, 2000; Wang等, 2000; Chen等, 2018). 
Xie和Wang(2020)认为PDO和热带印度洋的海温异常 可以通过阿留申低压和沃克环流协同影响WNPAC的 年代际变化. 为此, 本文将从热带印度洋海温年代际变 化的角度探讨其对 2020 年超强梅雨的可能贡献，以期 为改进我国长江流域极端强降水的预报能力提供线索 和参考.

\section{2 数据与方法}

\section{1 数据}

所用的资料包括：(1) 1979年1月 2020年7月美国 国家气候预测中心 (CPC)逐日降水数据(https://ps1. noaa.gov/data/gridded/data.cpc.globalprecip.html)，水平 分辨率为 $1^{\circ}$ (Xie等, 2007)；(2) 2020年1月 7月国家气 象信息中心(NMIC)逐小时融合降水资料(包含台站观 测、卫星观测和雷达观测)，水平分辨率为 $0.05^{\circ}$ (潘旸 等, 2015); (3) 1979 2020年逐月NOAA第5版海温资料 (ERSSTV5) (Huang等, 2017); (4) 1979 2020年NCEP/ DOE第二套逐月再分析资料，包括 $1000 \sim 300 \mathrm{hPa}$ 风 场、温度场、相对湿度场、位势高度场和 $500 \mathrm{hPa}$ 垂直 速度场，水平分辨率为 $2.5^{\circ}$ (Kanamitsu等，2002)。除融 合降水资料外，所有数据集均由NOAA物理科学实验 室(PSL)提供(https://psl.noaa.gov/). 此外，本文根据克 劳修斯-克拉佩龙方程计算得出比湿场，所用程序由 NCAR旗下软件NCL提供(https://www.ncl.ucar.edu/ Document/Functions/Built-in/mixhum_ptrh.shtml).

\section{2 统计方法}

本文取1979 2020年逐月平均值为气候态. 为提取 气候要素场的年代际分量, 主要使用谐波分解进行 9 年 以上的低通滤波处理. 此外，根据公式(1)定量地衡量 气候要素场的年代际分量对原始序列的方差贡献(简 称 $V C$ ).

$V C=\frac{\sum_{1}^{N}\left(\widetilde{x_{i}^{\prime}}\right)^{2}}{\sum_{1}^{N}\left(x_{i}^{\prime}\right)^{2}} \times 100 \% \quad(i=1,2, \cdots N)$.

以降水场为例， $x^{\prime}$ 代表1979 2020年的降水异常值，样 本数 $N$ 为 $42 ; x^{\prime}$ 代表谐波分解后降水异常的年代际分 量. $V C$ 实际上指代了气候变量年代际分量的方差与原 始方差之比, 也可被称为解释方差.
为检验滤波后气候要素场的显著性，本文采用蒙 特卡洛方法. 以回归分析的显著性检验为例, 其步骤 如下：首先，计算得到每个网格点上某时间系数与气 候要素场的回归系数 $y_{a}$; 将时间系数随机排序后计算 得出新的回归系数 $y_{b}$; 此过程重复 1000 次, 即有 $y_{b i}$ $(i=1,2,3, \cdots, 1000)$; 对比 $y_{a}$ 和升序排列之后的 $y_{b i}(i=1$, $2,3, \cdots, 1000)$, 若 $y_{a}$ 大于 $97.5 \%$ (95\%)或小于 $2.5 \%(5 \%)$ 的 $y_{b}$ 集合，则认为 $y_{a}$ 通过 $95 \%(90 \%)$ 置信度检验. 相关 系数的蒙特卡洛检验方法与之类似.

\section{3 数值模式}

通用地球系统模式(CESM)由地球大气、海洋、 陆地、陆-冰和海-冰五个主模块组成. 其中大气模块 CAM5 (Community Atmospheric Model, version 5.3) 被视为研究海温异常影响大气环流的重要工具之一 (Neale等，2012)。本文采用CAM5模式(经纬度分辨率 设置为 $\left.1.25^{\circ} \times 0.9^{\circ}\right)$ 探讨大气环流对热带西印度洋 (TWI)海表温度变化的响应. 控制试验中海温和海冰设 置为包含年循环的气候平均态，以此模拟真实大气环 流的平均状态. 为研究大气环流对TWI地区海温异常 的响应，本文设计了一组敏感性试验(简称TWI试验), 即在气候平均态上叠加 2020 年4 7月 TWI地区 $\left(15^{\circ} \mathrm{S}\right.$ $\left.\sim 15^{\circ} \mathrm{N}, 45^{\circ} \mathrm{E} \sim 80^{\circ} \mathrm{E}\right)$ 的异常海温强迫, 其量值与 2020 年 春末夏初TWI地区海温的年代际增暖保持一致. 两组 试验均积分 20 年，将第 $5 \sim 20$ 年的平均值视为大气环流 的响应结果.

\section{2020年长江流域超强梅雨}

\section{1 超强梅雨及其环流特征}

2020年6 7月, 主要强降水过程位于长江中下游地 区, 范围覆盖淮河流域、长江流域和西南局部地区(图 $1 \mathrm{a}$ 和 $1 \mathrm{~b})$ ，两套降水资料所得结果一致，因此后文只给 出基于 CPC 降水资料分析的相关结果. 本文重点关注 $\left(27^{\circ} \mathrm{N} \sim 33^{\circ} \mathrm{N}, 106^{\circ} \mathrm{E} \sim 122^{\circ} \mathrm{E}\right)$ 的长江中下游地区，将其 区域平均的标准化降水序列定义为长江流域降水指数 (简称YRVRI). 图2a为6 7月平均YRVRI的逐年变化情 况，尽管1998年和2016年皆为强El Niño衰减年, 使长 江流域遭遇了严重的洪涝灾害(图3), 但对比分析发现, 2020年长江流域降水为历史最多，梅雨期的降水强度 远远高于传统涝年，甚至是1998年和2016年的两倍之 
(a) 6 7月YRVRI
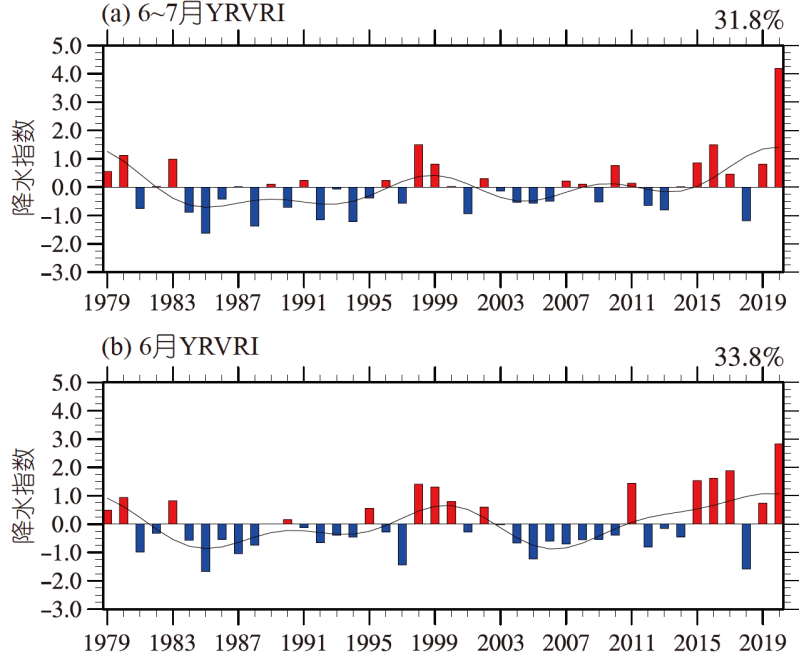

(c) 7月YRVRI

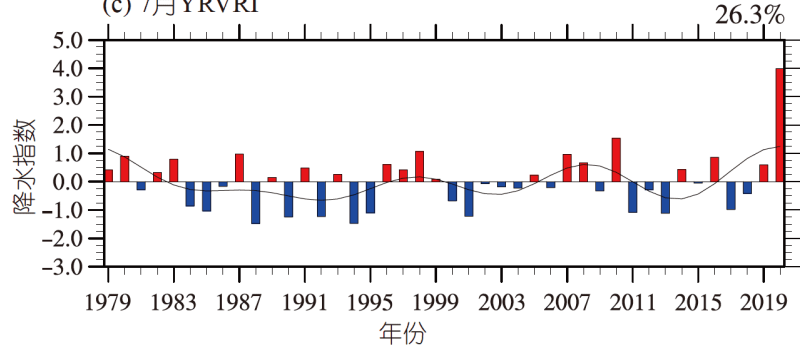

图 2 1979 2020年夏季长江流域降水指数YRVRI(柱状图) 的时间序列及其年代际分量(黑实线)

(a) 6 7月YRVRI; (b) 6月YRVRI; (c) 7月YRVRI. 图右上数字为年代 际分量的方差贡献 $(\mathrm{VC})$

多. 因此, 如何准确预报超强梅雨成为了社会各界的关 注热点，分析2020年超强梅雨成因则是解答这一科学 问题的基础.
图 $4 \mathrm{a}$ 为 2020 年春末夏初长江流域降水的逐日分 布. 由图可知, 从6月2日开始, 强降水过程频繁发生并 且一直持续到 7 月末，7月降水强度和降水日数均明显 高于6月，且7月累积降雨量的增长速率明显高于 1998 年和2016年(图4b). 然而, 2020年6月和7月长江流域降 水异常的特征存在明显差异. 这与Liu等(2020)的工作 相一致. 他们认为 2020 年6月梅雨带是暖锋性质，而7 月是冷锋性质, 这一转变与北大西洋涛动 $(\mathrm{NAO})$ 的位 相转换有关. 这意味着2020年超强梅雨在6月和7月的 特征及其形成机制可能存在较大差异.

为了探讨超强梅雨期间长江流域的水汽输送情 况，本文计算了 2020 年6月和7月整层积分 $(1000 \mathrm{hPa}$ 至 $300 \mathrm{hPa}$ ) 的水汽通量、水汽通量散度(图 $5 \mathrm{a}$ 和 $5 \mathrm{~b}$ )、 $850 \mathrm{hPa}$ 位势高度和水平风场异常(图6a和6b). 可见 2020年6月长江流域主要有两个水汽来源：其一源自 中南半岛附近的异常西南风(图6a), 异常水汽由中南 半岛西北部 $\left(20^{\circ} \mathrm{N}, 90^{\circ} \mathrm{E}\right)$ 一直输送到 $110^{\circ} \mathrm{E} \sim 120^{\circ} \mathrm{E}$ 附近 (图5a); 其二则源自南海北部, 经由WNPAC西侧的异 常西南风(图6a)输送至 $25^{\circ} \mathrm{N}$ 以南的华南地区(图5a). 两 条水汽输送带在中南半岛东北部汇聚后, 进一步向北 扩张到长江流域，从而导致长江流域出现显著的水汽 辐合(图5a). 由此可见, 长江流域水汽输送的增强是导 致2020年6月长江流域降雨显著增多的直接原因.

2020 年7月，南亚地区 $\left(\right.$ 约 $\left.10^{\circ} \mathrm{N} \sim 25^{\circ} \mathrm{N}\right)$ 有一带状分 布的异常副热带高压，并向东北方向延伸至副热带北 太平洋(约 $\left.35^{\circ} \mathrm{N}\right)$ (图6b). 孟加拉湾北部的异常西风和中 南半岛东北部的异常西南风将南亚季风区的暖湿空气 (a) 1998年6 7月(CPC)

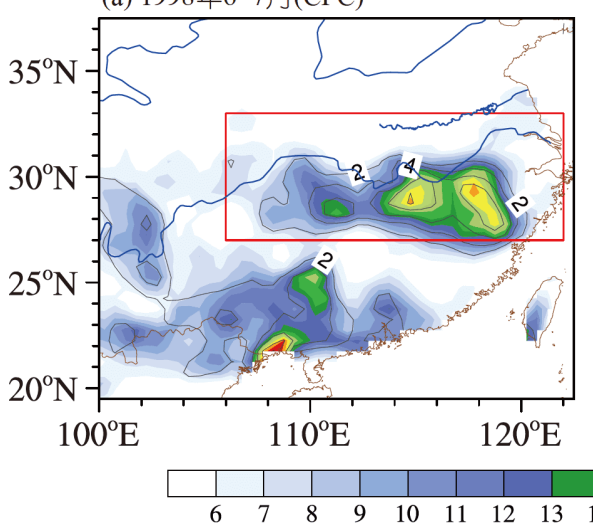

(b) 2016年6 7月(CPC)

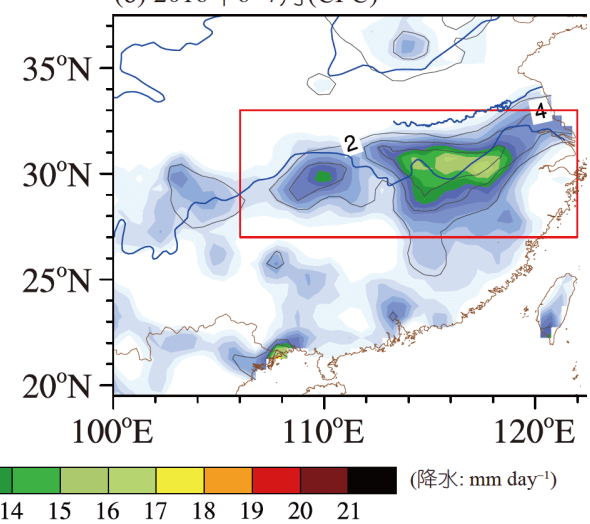

图 $36 \sim 7$ 月长江流域降水及其异常的空间分布

(a) 1998年, (b) 2016年. 填色为降水数据, 等值线为降水异常, 单位 $m m$ day $^{-1}$, 起始等值线为 $2 \mathrm{~mm} \mathrm{day}^{-1}$, 间隔为 $2 \mathrm{~mm} \mathrm{day}^{-1}$ 

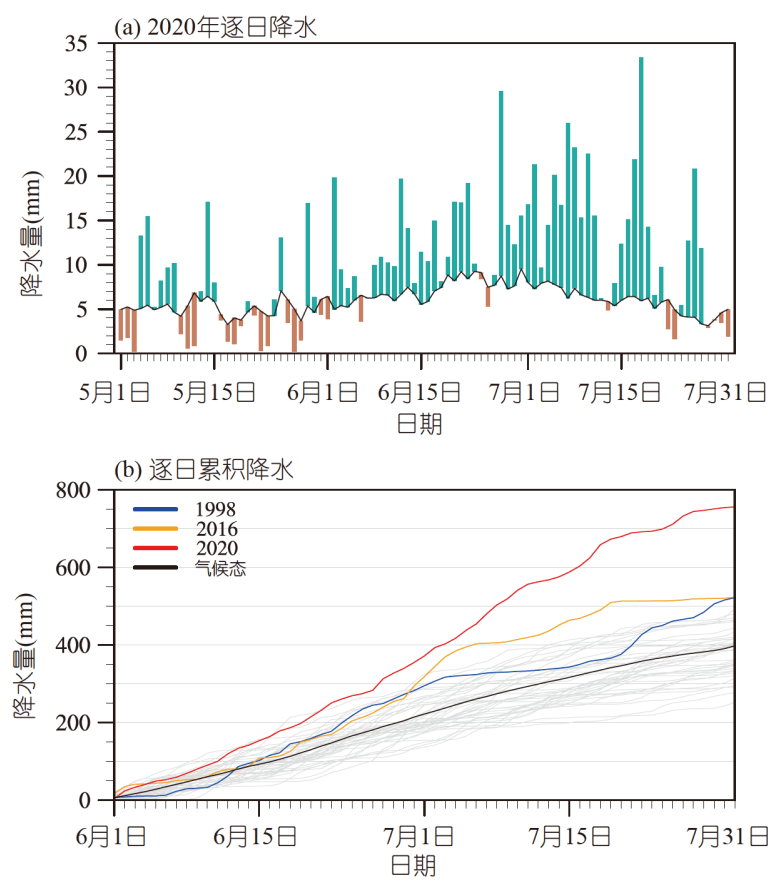

图 4 长江流域逐日和累计降水量的时间序列 (a) 2020年5月1日 7月31日逐日降水量; (b) 1979 2020年6月1日 7 月31日累计降水量

输送到长江流域(图 5b)，有利于强降雨的发生. WNPAC西侧的西南风是长江流域充沛水汽的主要输
送源，表明与之相关的西太平洋副热带高压对长江流 域的降水至关重要. 对比分析发现，6月长江流域受西 南风主控(图6a)，7月朝鲜半岛南部有显著的异常气旋 性环流(图6b), 其东南侧的异常北风有利于冷空气南 下，致使冷暖空气于长江流域对峙，意味着7月长江流 域降水可能与中纬度环流异常联系更加紧密. Liu等 (2020)也发现，2020年6月30日至7月13日的梅雨与南 亚高压和中纬度蒙古气旋的协同变化有关，来自北方 的冷空气南下造成该时段的梅雨锋表现为明显的冷锋 结构.

虽然7月长江流域降水较6月偏多，但就年代际尺 度而言，6月降水的年代际信号明显强于7月，因此本 文侧重于讨论6月长江流域降水的变化及副热带地区 WNPAC的可能影响.

参考Wang等 $(2001)$ 的工作, 将 $5^{\circ} \mathrm{N} \sim 15^{\circ} \mathrm{N}, 100^{\circ}$ $\mathrm{E} \sim 130^{\circ} \mathrm{E}$ 与 $20^{\circ} \mathrm{N} \sim 30^{\circ} \mathrm{N}, 110^{\circ} \mathrm{E} \sim 140^{\circ} \mathrm{E}$ 区域平均的 $850 \mathrm{hPa}$ 纬向风之差定义为西北太平洋季风指数 (WNPMI), 以此表征西北太平洋地区大气环流的变化 情况. 当WNPMI为负(正)值时, 西北太平洋地区为反 气旋(气旋)性环流，夏季长江流域的降水趋于增强(减 弱)(Wang和Lin, 2002). 在1979 2020年期间, WNPMI 和6月、7月YRVRI呈现反相变化(图7a和7b)，其相关 (a) 2020 年6月

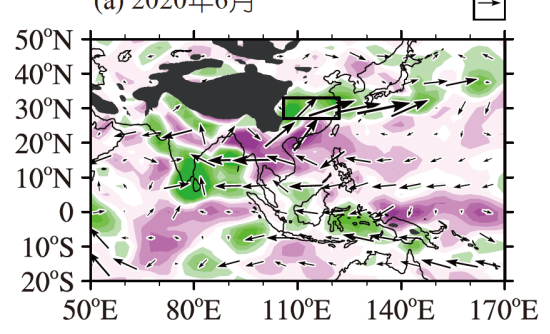

(b) 2020 年7月

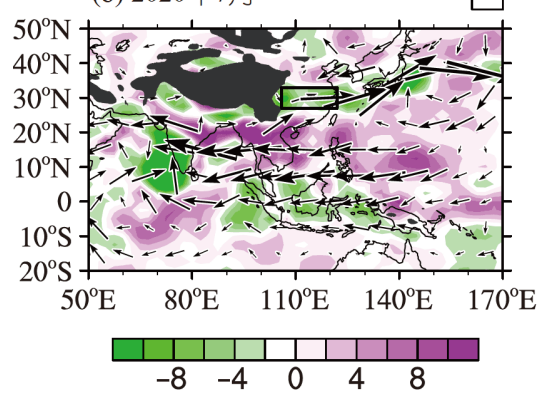

(c) 2020 年 6 月 $(\geq 9$ 年)

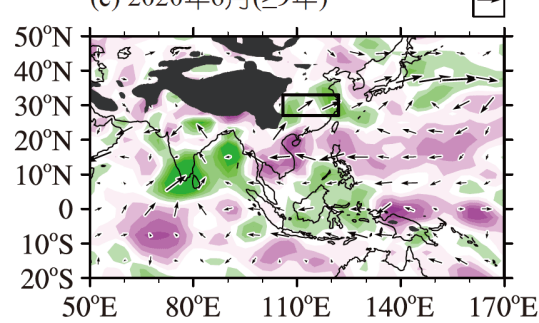

(d) 2020 年7月( $\geq 9$ 年)

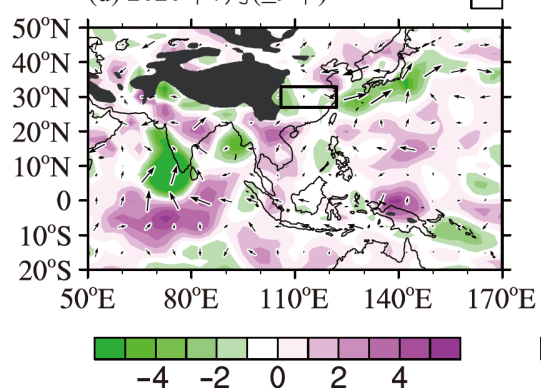

(e) 6 月 ( $\geq 9$ 年)

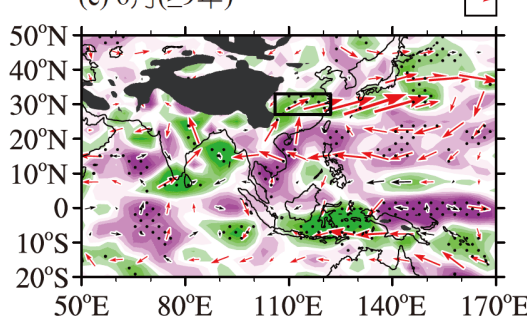

(f) 7 月( $\geq 9$ 年)

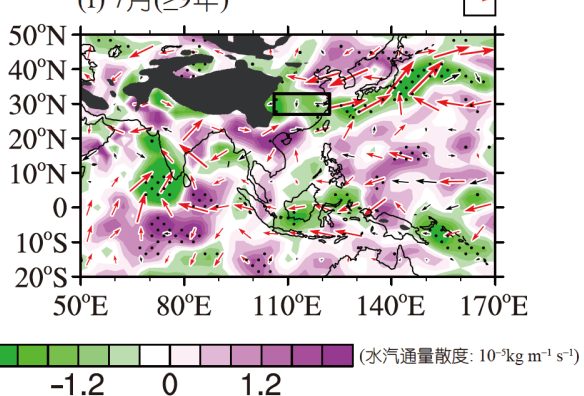

图 5 垂直积分的水汽通量和水汽通量散度异常的空间分布

(a) 2020年6月; (b) 2020年7月; (c) 2020年6月的年代际分量; (d) 2020年7月的年代际分量; (e) 6月YRVRI与同期水汽通量(红色矢量代表超过95\% 置信度)及其散度(打点代表 $95 \%$ 置信度, 单位: $10^{-5} \mathrm{~kg} \mathrm{~m}^{-2} \mathrm{~s}^{-1}$ ) 年代际分量的回归; (f) 7月YRVRI与同期水汽通量及其散度年代际分量的回归 

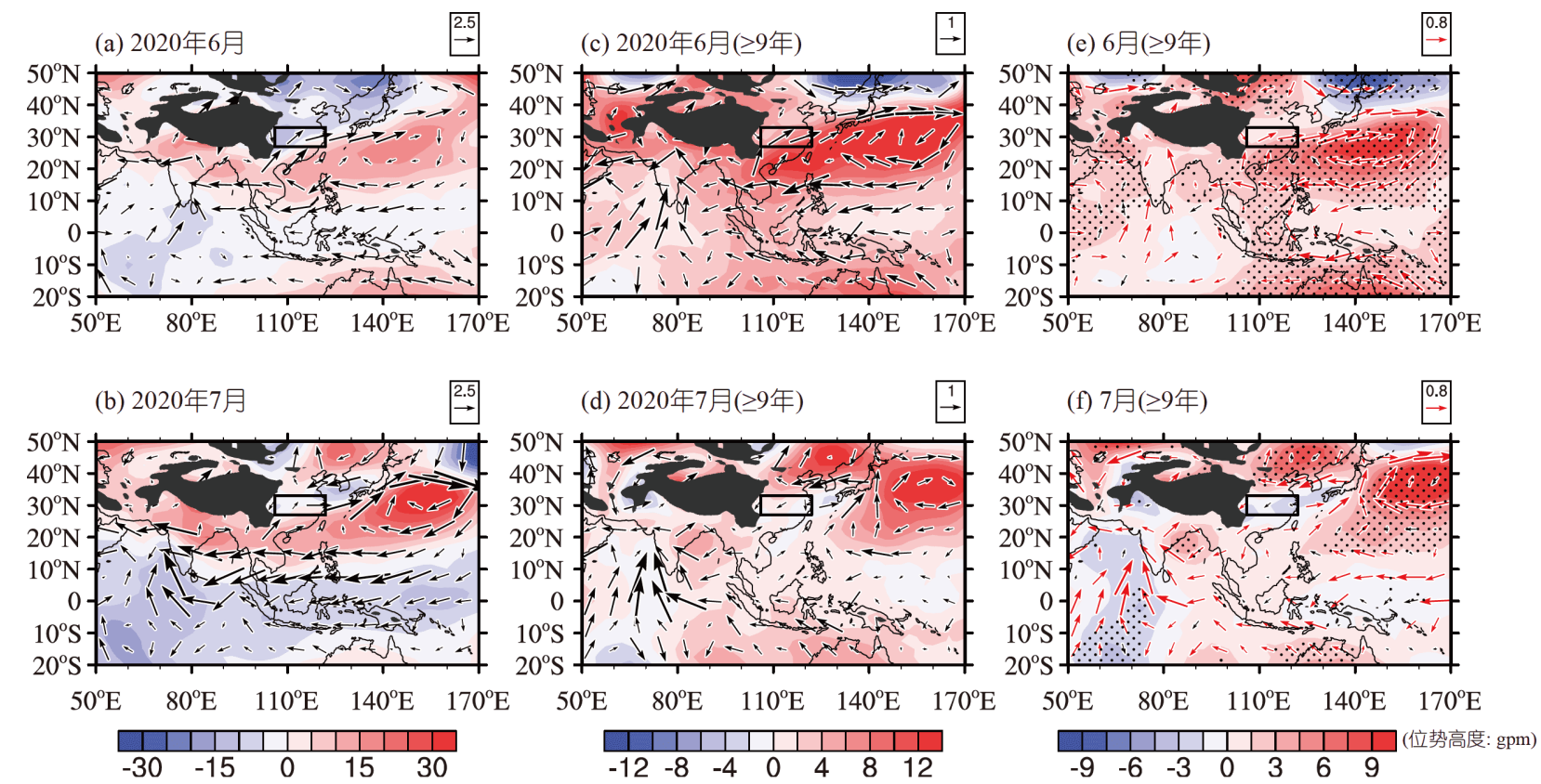

图 $6850 \mathrm{hPa}$ 位势高度异常和 $850 \mathrm{hPa}$ 水平风异常

同图5. 填色为位势高度异常, 单位: gpm; 矢量为水平风异常, 单位: $\mathrm{m} \mathrm{s}^{-1}$

系数分别为 -0.45 和 -0.44 . 为进一步探讨梅雨期降水与 WNPAC的关系，根据6 7月平均的YRVRI指数选取了 研究时段内梅雨降水最强的 5年(即1980、1983、 1998、2016和2020年)进行对比，可见2020年5 6月 WNPMI的绝对值在 5 年中最大(图7c)，表明2020年中 国东部地区的极端异常的反气旋式环流可能是导致超 强梅雨发生的重要原因.

\section{2 长江流域梅雨的年代际变化}

2020年梅雨期降水年代际分量的空间分布呈现出 中国东部降水异常偏多的形势，最大降水中心位于安 徽省(图1c)，其空间部分类似于未经滤波处理的降水 异常(图1b中等值线). 进一步估算1979 2020年梅雨期 内YRVRI指数及其年代际分量的方差占比可知，其年 代际分量占降水总体方差的 31.8\%(图2a)，表明梅雨期 降水的年代际变率对2020年超强梅雨有重要贡献.

从2020年6月和7月长江流域降水年代际分量的空 间分布上看, 6月主要降水区集中在长江中下游和华南 地区，其年代际分量对降水总体方差的贡献几乎都超 过了 $40 \%$ (图1d); 7月主要降水区集中在湖北、安徽、 广西等地, 最大降雨中心位于 $30^{\circ} \mathrm{N} 、 118^{\circ} \mathrm{E}$ 附近, 但是 年代际分量的方差贡献基本小于 $40 \%$ (图1e). 从 6 月和7
月YRVRI指数来看(图2b)，7月YRVRI年代际分量的解 释方差 $(26.3 \%)$ 也明显小于 6 月 (33.8\%). 为进一步验证6 月和7月长江流域降水在年代际尺度上的差异, 使用小 波分析对比分析了1979 2020年6 7月长江流域降水 的主导周期(图略). 结果显示6月YRVRI指数存在准 18 年的周期, 而7月YRVRI的年代际周期并不显著, 表明 6 月长江流域降雨的年代际变化特征比7月更加明显.

图 $5 c$ 和图 $6 c$ 显示，在年代际时间尺度上，2020年6 月我国华南和副热带西北太平洋地区为反气旋式环流 控制，WNPAC异常偏西(图6c)，与之相伴随的异常西 南风将丰沛的水汽源源不断地输送到长江流域(图5c), 局地加强的水汽辐合有利于当地降水的增多; 2020年7 月，盘踞在我国华南地区的异常反气旋撤退至日本附 近, 长江流域地区转为微弱的异常东北风(图6d), 水汽 输送通道随之中断(图5d).

以上分析了 2020 年梅雨期内大气环流的年代际调 整，随后我们进一步计算了1979 2020年内YRVRI指 数与对流层低层大气环流年代际分量的回归. 比较图 $5 \mathrm{e}$ 和图6e两幅图可以发现, 当6月长江流域降雨呈现年 代际增强时, 异常WNPAC覆盖了我国华南和副热带西 北太平洋地区(图6e), 长江流域有明显的水汽辐合, 这 与2020年6月年代际尺度的环流异常特征十分类似(图 

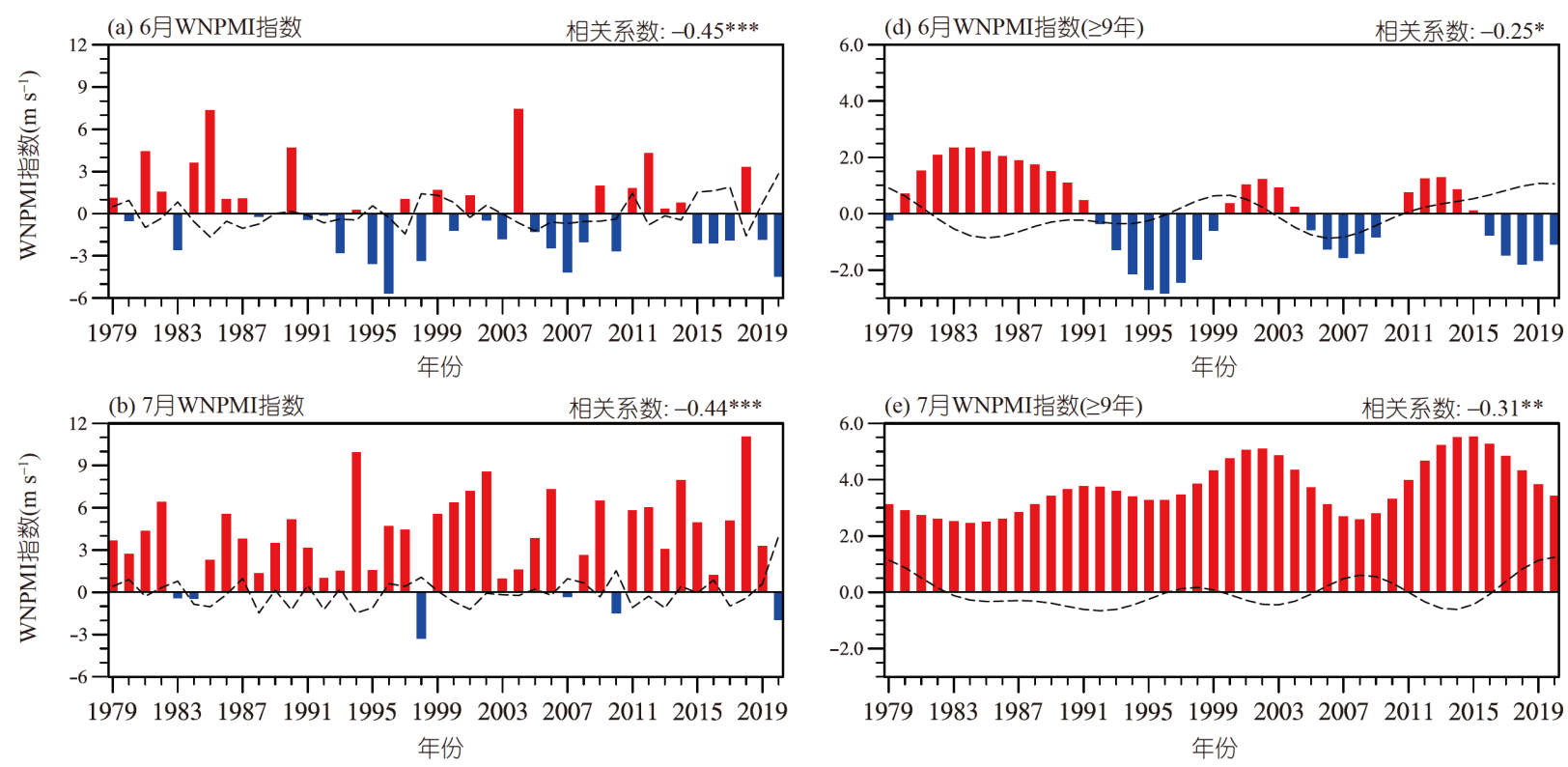

(c) 强梅雨年WNPMI指数
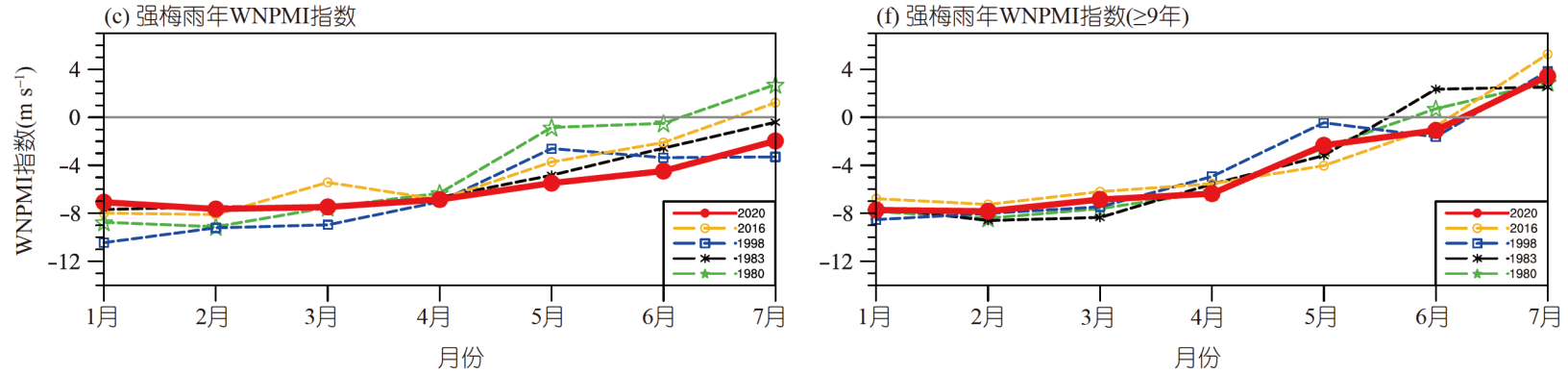

图 7 1979 2020年WNPMI(柱状)和YRVRI(黑线)指数((a) (c))及其年代际分量的时间序列((b) (f))

(a), (d) 6月; (b), (e) 7月; (c), (f) 强梅雨年. * **、**分别表示 $90 \% 、 95 \% 、 99 \%$ 置信度

$5 \mathrm{c}$ 与图 $6 \mathrm{c})$. 然而，当7月降雨呈现年代际增强时，显著 的反气旋式环流不再位于我国华南地区，取而代之的 是一微弱的气旋式环流, 其西侧较弱的东风异常(图 6f)无法给长江流域带来充沛的水汽(图5f)，这也部分 解释了7月长江流域降水年代际信号相对微弱的原因. 此外，7月长江流域以北环流信号的明显加强，表明中 纬度系统对2020年7月降水的贡献不容忽视, 需要更加 深入的研究以揭示超强梅雨的成因.

图7d给出了1979 2020年6月WNPMI年代际分量 的变化曲线, 可见2015年之后6月WNPMI的年代际分 量均为负值，表明2020年正处于我国华南地区反气旋 式环流偏强的年代际背景之下；而7月其年代际分量 一直维持正值 (图7e), 表明在年代际尺度上7月我国华 南地区始终被气旋式环流异常控制，这将不利于大气 环流对长江流域的水汽输送. 此外, 图5f和图6f显示, 7 月华南大部分地区的环流异常十分微弱且不显著. 由
此推断，7月异常WNPAC的年代际异常对当月长江流 域降水的贡献可能较小. 因此, 后文主要讨论6月长江 流域降水异常的成因.

\section{4 热带海温的年代际异常对超强梅雨的可 能贡献}

\section{1 观测结果}

已有的工作表明, WNPAC的异常变化与热带地区 海温异常密切相关(Wang等, 2000; Wu等, 2009, 2010a; Xie等, 2009). 为探究WNPAC年代际变化的成因, 分析 了2020年6月热带印度洋和西太平洋地区的海温、 $500 \mathrm{hPa}$ 垂直速度异常及其年代际分量(图8a和 $8 \mathrm{~b}$ ). 由 图8a可以清楚地看到, 2020年6月长江流域发生强降水 时，整个热带印度洋以及西太平洋地区均出现了异常 增暖，并伴随着大范围的异常上升运动，我国 $35^{\circ} \mathrm{N}$ 附 
(a) 2020 年6月

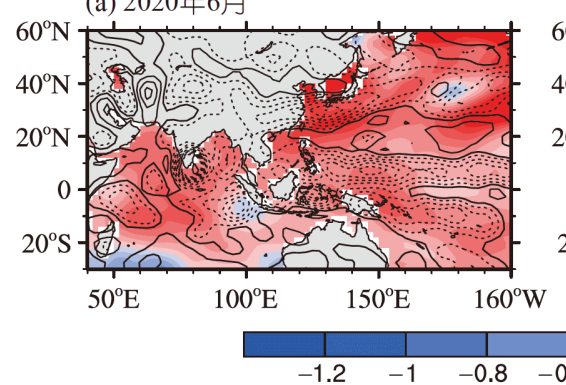

(b) 2020 年6月( $\geq 9$ 年)

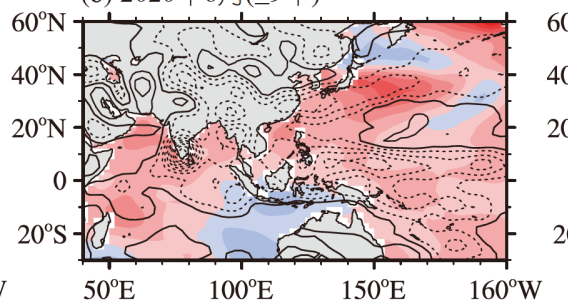

(c) 6 月 $(\geq 9$ 年)

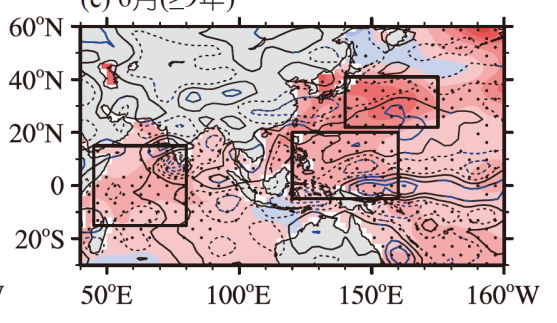

图 8 海温异常和 500hPa垂直速度异常的空间分布

(a) 2020年6月; (b) 2020年6月的年代际分量; (c) 6月YRVRI与同期海温(打点代表 $95 \%$ 置信度)及垂直速度(间隔为 $0.004 \mathrm{~Pa} \mathrm{~s}{ }^{-1}$, 蓝色等值线代表 超过 $95 \%$ 置信度)年代际分量的回归. 填色为海温异常, 单位: ${ }^{\circ} \mathrm{C}$; 等值线为垂直速度异常, 单位 $\mathrm{Pa} \mathrm{s}^{-1}$, 起始值为 $0.01 \mathrm{~Pa} \mathrm{~s}^{-1}$, 间隔为 $0.03 \mathrm{~Pa} \mathrm{~s}$. 其 中黑框分别代表热带西印度洋(TWI: $\left.15^{\circ} \mathrm{S} \sim 15^{\circ} \mathrm{N}, 45^{\circ} \mathrm{E} \sim 80^{\circ} \mathrm{E}\right)$, 热带西太平洋(TWP: $5^{\circ} \mathrm{S} \sim 20^{\circ} \mathrm{N}, 120^{\circ} \mathrm{E} \sim 160^{\circ} \mathrm{E}$ )以及西北太平洋(WNP: $22^{\circ} \mathrm{N} 41^{\circ}$ $\left.\mathrm{N}, 140^{\circ} \mathrm{E} \sim 175^{\circ} \mathrm{E}\right)$

近的异常上升运动带对应着长江流域强降水. 从年代 际分量看，6月TWI、热带西太平洋(TWP)和西北太平 洋(WNP)也都出现了明显的年代际增暖(图8b). 此外, 热带东南印度洋地区出现了小范围的冷海温异常, 它 与其西北侧的异常增暖海形成了类似热带印度洋偶极 子(IOD) (Saji等, 1999)的空间分布. 但是类IOD的分布 型并未出现(图8c)，6月YRVRI与同期海温年代际分量 的回归场中, 取而代之的是印度洋海盆一致的增暖信 号, 暖中心位于 $\left(0^{\circ}, 60^{\circ} \mathrm{E}\right)$ 附近.

相应的 $500 \mathrm{hPa}$ 垂直速度异常表明, TWI地区的西 部和东北部有较弱的异常上升流; 在WNP地区, 垂直 速度异常呈经向的偶极型分布, $35^{\circ} \mathrm{N}$ 以北为较弱的上 升运动, 以南为显著的下沉运动; TWP地区的垂直速 度异常呈经向三极型分布, 即TWP北部和南部有显著 下沉运动, $5^{\circ} \mathrm{N}$ 附近有带状分布的异常上升运动(图 $8 \mathrm{c})$. WNP和TWP地区以下沉运动为主、上升运动范 围较小且不显著的特征, 表明两地的海温异常很可能 受到了大气环流的有效调制, 其对大气的主动影响十 分有限.

将三个关键区(TWI: $15^{\circ} \mathrm{S} \sim 15^{\circ} \mathrm{N}, 45^{\circ} \mathrm{E} \sim 80^{\circ} \mathrm{E}$; WNP: $22^{\circ} \mathrm{N} \sim 41^{\circ} \mathrm{N}, 140^{\circ} \mathrm{E} \sim 175^{\circ} \mathrm{E}$; TWP: $5^{\circ} \mathrm{S} \sim 20^{\circ} \mathrm{N}$, $120^{\circ} \mathrm{E} \sim 160^{\circ} \mathrm{E}$ ) 区域平均的异常海温定义为海温指数, 分别简称为TWII, WNPI以及TWPI. 6月YRVRI与前期 1 7月不同海温指数的年代际相关结果表明, 6月YRV$\mathrm{RI}$ 与前期 4 月 TWII的相关最高(约为 0.70 ), 随后 6 月相 关系数减弱至 0.55 , 但仍然超过了 $95 \%$ 置信度(图9a), 表明前期印度洋的增暖有可能会通过调制大气环流影 响我国夏季降水. 已有的数值模式结果表明, 在ENSO
暖事件达到成熟期和衰减期, 热带印度洋海温会直接 影响西北太平洋地区的大气环流(Watanabe和Jin, 2002). 然而, 近期的观测分析表明在成熟期冬季和衰 减期春季, 热带印度洋海温异常是由大气环流强迫所 致, 直至衰减期夏季热带印度洋海温异常才能够对 WNPAC产生主动影响(Wu等，2009，2010； Li等, 2017). 因此，尽管发现前期4月TWII与长江流域降水 的相关最高, 但此时热带印度洋能否主动影响周边大 气环流仍然需要进一步讨论.

为此, 进一步分析了年代际时间尺度上前期 4 5月 的海温与 $500 \mathrm{hPa}$ 垂直速度异常的对应关系(图 10). 如 图所示, 4月份, 印度洋海盆尺度的异常增暖伴随着东 北-西南走向的垂直速度异常三极型分布: 热带印度洋 $\left(0^{\circ} \sim 17^{\circ} \mathrm{S}, 60^{\circ} \mathrm{E} \sim 85^{\circ} \mathrm{E}\right)$ 范围内有显著的异常下沉运动, 其西南侧 $\left(0^{\circ} \sim 20^{\circ} \mathrm{S}, 40^{\circ} \mathrm{E} \sim 60^{\circ} \mathrm{E}\right)$ 和东北侧 $\left(5^{\circ} \mathrm{N} \sim 20^{\circ} \mathrm{S}\right.$, $90^{\circ} \mathrm{E} \sim 100^{\circ} \mathrm{E}$ ) 有较弱的异常上升运动(图10a). 在TWI区 域(经度范围 $45^{\circ} \mathrm{E} \sim 80^{\circ} \mathrm{E}$ ) 绝大部分地区的异常增暖对 应着显著的异常下沉运动, 表明TWI地区的海温异常 并不能主动地调制大气环流. 与4月不同, 5 月份 TWI 的增暖信号出现显著加强, 其最大增暖中心达 $0.3^{\circ} \mathrm{C}$ 位于 $\left(0^{\circ}, 55^{\circ} \mathrm{E}\right)$ 附近, 对应着TWI地区较大范围的异常 上升运动(图10b). 这表明自5月起, TWI地区的异常增 暖逐渐开始主动加热大气, 在局地产生异常上升运动. 6月份TWI地区显著的异常上升运动仍然可见(图8c), 表明TWI地区异常增暖对局地大气环流的强迫作用可 由前期 5 月维持到同期 6 月, 通过改变季风区垂直环流 进而引发WNPAC异常(图11d), 导致长江流域地区出 现异常水汽辐合(图11a). 图9b显示, 自21世纪初期之 
(a) 超前滞后相关 $(\geq 9$ 年)

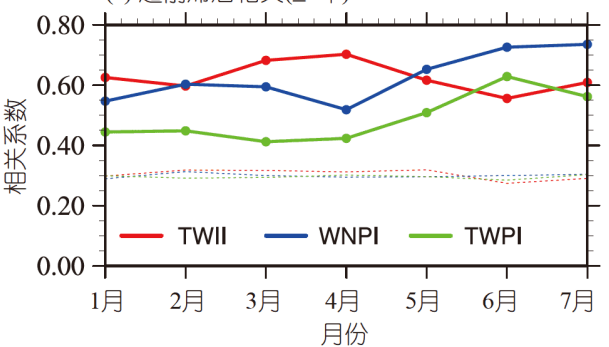

(c) 6 月WNPI

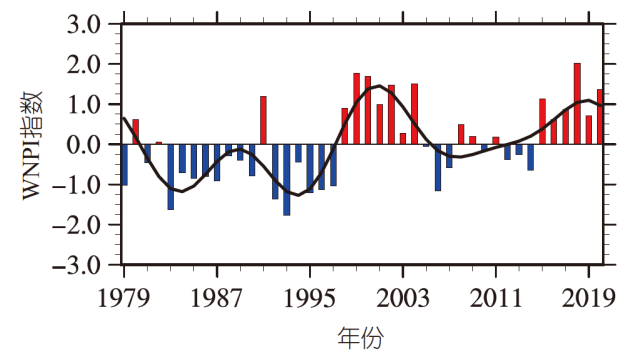

(b) 5 月TWII

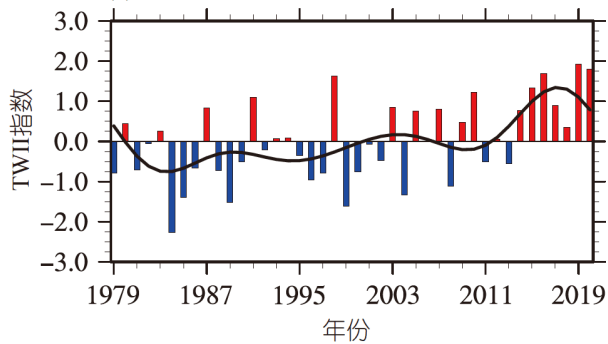

(d) 6 月TWPI

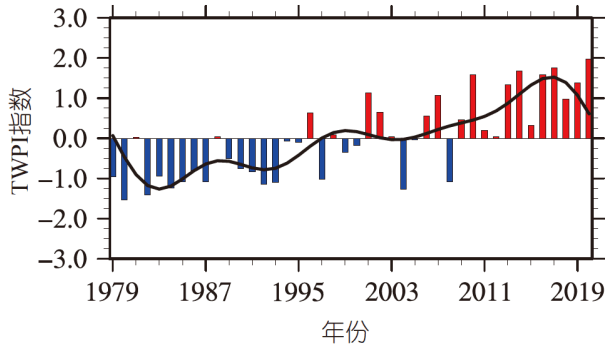

图 9 降水与海温指数的超前滞后相关及海温指数的标准化时间序列

(a) 6 月YRVRI指数与前期 1 7月海温指数年代际分量的相关; (b) 5 月 TWII指数及年代际分量; (c) 6 月WNPI指数及年代际分量: (d) 6 月 TWPI指 数及年代际分量. (a)中虚线代表 $95 \%$ 置信度

(a) 4 月

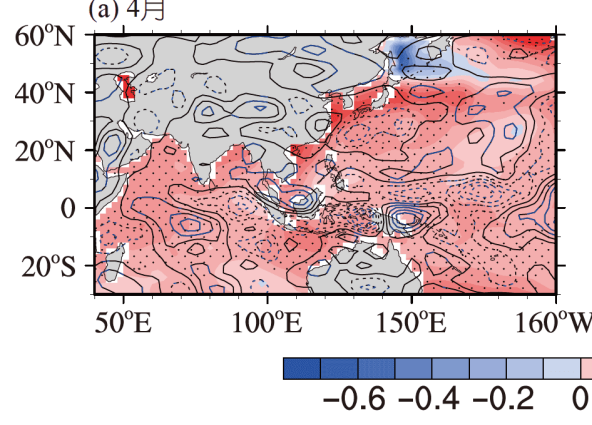

(b) 5 月

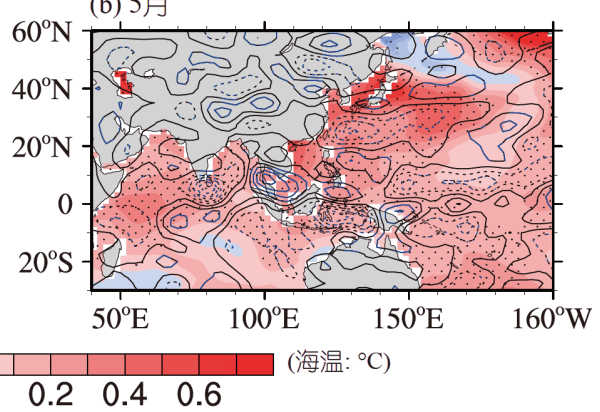

图 10 6月YRVRI指数与前期海温异常和 $500 \mathrm{hPa}$ 垂直速度异常年代际分量的回归

(a)前期4月; (b)前期 5 月. 填色为海温异常, 单位: ${ }^{\circ} \mathrm{C}$, 打点代表 $90 \%$ 置信度; 等值线为垂直速度异常, 单位: $\mathrm{Pa} \mathrm{s}^{-1}$, 间隔为 $0.08 \mathrm{~Pa} \mathrm{~s}{ }^{-1}$, 蓝色等值线 代表90\%置信度)

后, 5 月TWII指数表现出明显的年代际增暖, 这一增暖 的年代际调整，为长江流域提供了有利的水汽条件和 环流背景. 因此, 当 2020 年梅雨期内大气环流出现扰 动时, 极易与年代际背景相互作用, 从而导致超强梅 雨的出现.

值得注意的是, 2020年7月TWI地区的异常增暖仍 然存在(图略), 但其对长江流域降水的调制作用极其 微弱. 这可能与 7 月鄂霍茨克海附近的气旋式环流异 常有关(图6d), 中高纬度异常环流对WNPAC的调制作 用抵消了热带印度洋增暖的影响，致使在年代际时间 尺度上，2020年7月强降水的成因不再由热带信号主
导. 正如Liu等(2020)指出，2020年7月的梅雨与中纬度 大气环流关系更为紧密, 7月热带印度洋异常增暖对长 江流域降水的作用十分有限.

虽然WNP和TWP关键区海温指数与 6 月 YRVRI也 存在密切相关, 同期相关系数分别达为 0.73 (WNPI) 和 0.63 (TWPI). 但是, WNP (TWP)地区海温异常偏暖, 对 应着异常反气旋式环流(图11e和11f), 即局地暖海温对 应反气旋式异常, 表明WNP和TWP地区的异常增暖是 由局地反气旋强迫所致.

结合分析图11可知，TWII、WNPI、TWPI回归的 大气环流异常表现出较高的相似度, 这与三个指数之 

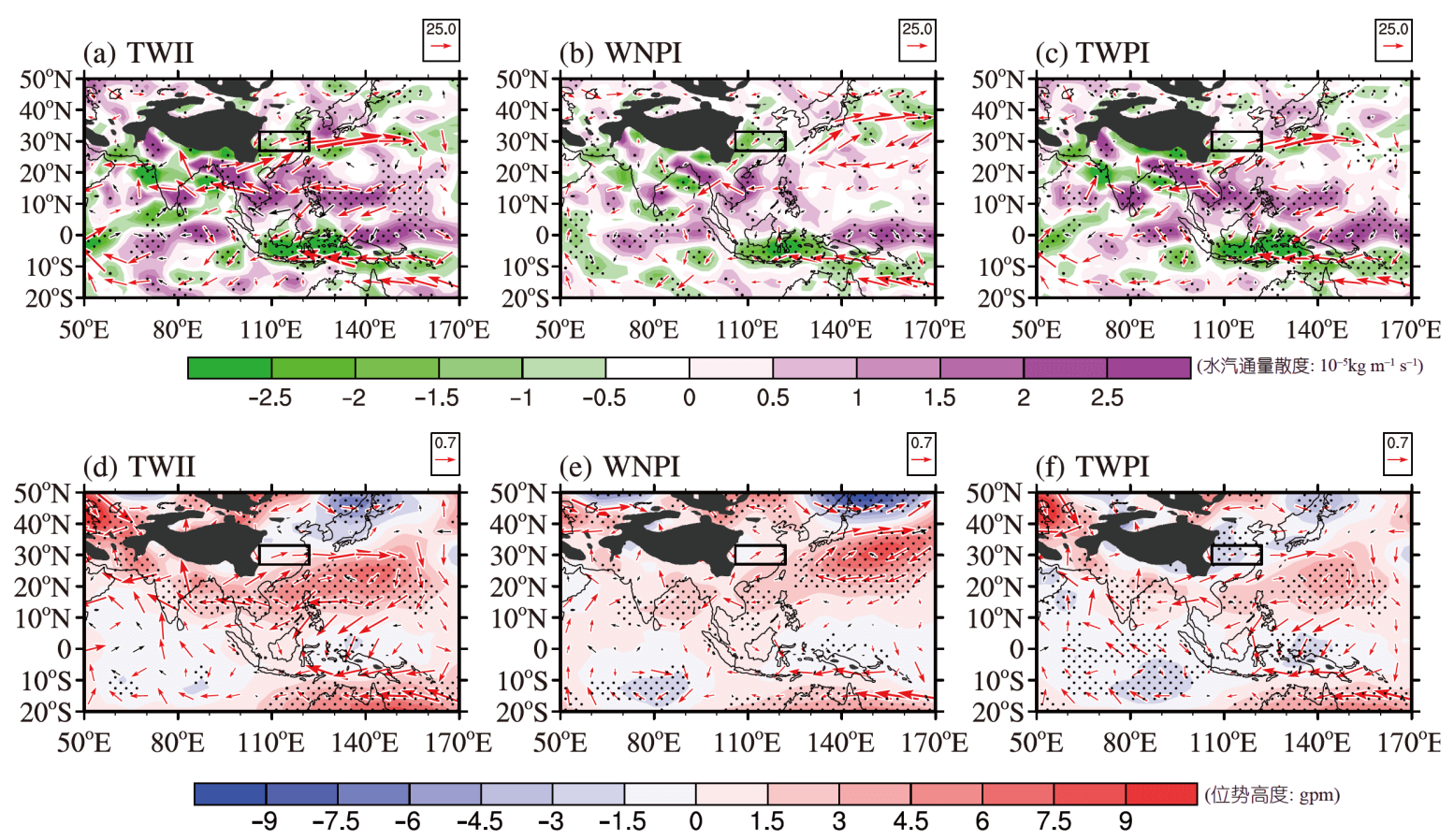

图 11 不同海温指数与 6 月垂直积分的水汽通量、散度异常((a) (c))和 $850 \mathrm{hPa}$ 水平风、高度异常 $((d) \sim(f))$ 年代际分量的回归 (a)和(d) 5月TWII; (b)和(e) 6月WNPI; (c)和(f) 6月TWPI. 水汽通量异常单位: $\mathrm{kg} \mathrm{m}^{-1} \mathrm{~s}^{-1}$, 红色矢量代表 $90 \%$ 置信度; 散度异常单位: $10^{-5} \mathrm{~kg}$ $\mathrm{m}^{-2} \mathrm{~s}^{-1}$, 打点代表 $90 \%$ 置信度. 水平风异常单位: $\mathrm{m} \mathrm{s}^{-1}$, 红色矢量代表 $90 \%$ 置信度; 位势高度异常单位: gpm, 打点代表 $90 \%$ 置信度

间相关较好有关. TWII与WNPI、TWII与TWPI以及 WNPI与TWPI的相关系数分别为 $0.48 、 0.84$ 以及 0.66 , 均通过了 $99 \%$ 的置信度检验. 采用偏回归方法可以分 离出TWI异常增暖对WNPAC的独立影响(图略), 其结 果与图11a和11d十分相似. 然而，只考虑WNP和TWP 地区异常增暖时, 仅在WNP和TWP地区有异常的局地 反气旋，长江流域的水汽条件较差(图略). 由此可见, 相比于WNP和TWP地区而言，TWI地区异常增暖对长 江流域降水年代际增多的作用更为重要.

此外, 1979 2020年三个海温指数的增暖趋势也不 容忽略(图9b 9d). 然而, 由于研究时段仅有 42 年, 无法 判断图中呈现的增暖趋势是源于全球变暖还是年代际 振荡. 简单考察了去趋势之后 5 月 TWII指数与 6 月 YRVRI的年代际相关，其系数可达 0.43 (通过 $90 \%$ 置信度), 表明这种联系并不受研究时段内增暖趋势的影响. 但 是, 如需明确全球变暖对热带印度洋海温年代际增暖 的作用, 仍然需要大量的工作加以研究.

\subsection{TWI试验结果}

图12为TWI试验中整层水汽通量和 $850 \mathrm{hPa}$ 大气环
流对TWI地区年代际增暖的异常响应场. 由图可知, 当 TWI地区海温增暖时，南亚至西太平洋地区的异常反 气旋式环流呈带状分布, 大值中心分别位于阿拉伯海 北部、孟加拉湾和中国台湾东侧(图12b). 异常反气旋 式环流西北侧的异常西南风, 将南海、热带西太平洋 地区的充沛水汽输送至长江流域(图12a), 与观测分析 的结果相似(图11a和 $11 \mathrm{~d}$ ), 为超强梅雨的发生提供了 有利的水汽条件. 模式试验进一步验证了 TWI地区的 年代际增暖，会强迫出有利于强降水发生的大尺度背 景环流场，致使长江流域6月降水明显增多. 然而，模 式试验中长江流域水汽辐合区 $\left(32^{\circ} \mathrm{N}\right.$ 附近 $)$ 较观测结果 明显偏北，这可能是由CAM5对东亚季风系统的模拟 偏差导致、Xie等(2016)利用CAM5模式研究气溶胶对 东亚夏季风的可能作用时也发现，模式对西太平洋副 热带高压的模拟比观测资料明显偏强、偏北.

\section{5 结论与讨论}

2020年6 7月, 我国长江流域遭受了近60年以来最 强梅雨的侵袭, 多地发生了严重的暴雨洪涝灾害. 本文 

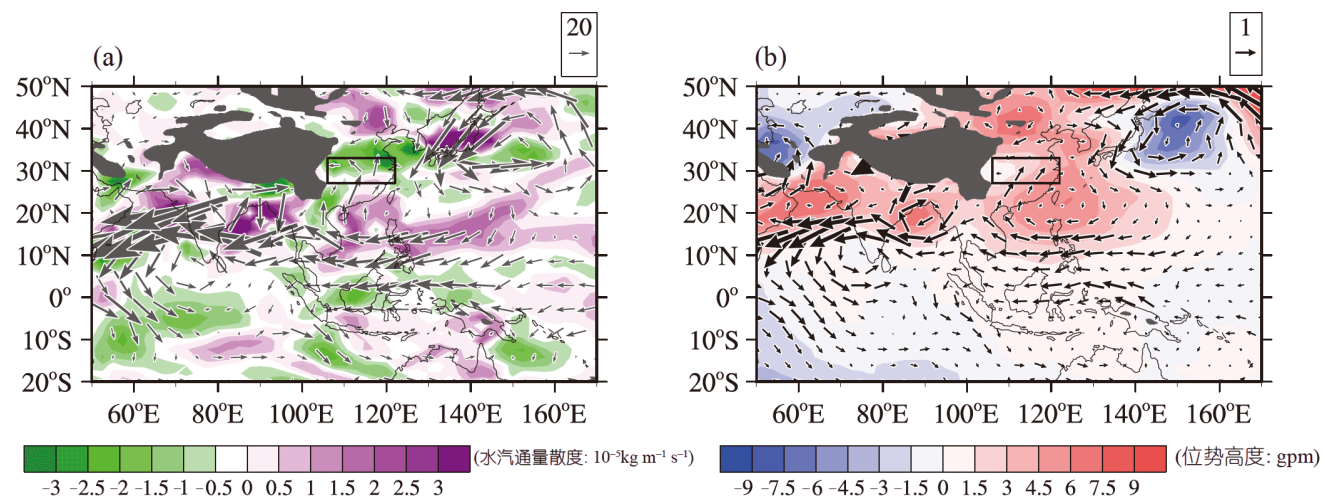

图 12 TWI试验与控制实验之差

(a) 垂直积分的水汽通量异常(单位: $\mathrm{kg} \mathrm{m}^{-1} \mathrm{~s}^{-1}$ )及其散度(单位: $10^{-5} \mathrm{~kg} \mathrm{~m}^{-2} \mathrm{~s}^{-1}$ ); (b) $850 \mathrm{hPa}$ 位势高度场异常(单位: gpm)及风水平异常(单位: $\mathrm{m} \mathrm{s}^{-1}$ )

通过对比分析6月和7月长江流域降水发现, 6月降水有 更加明显的年代际振荡，并与同期6月TWI、WNP和 TWP地区的海温异常均呈显著的年代际正相关. 进一 步研究发现, 虽然6月长江流域降水与TWI地区海温异 常的正相关可以追溯到前期4月，但此时TWI的海温异 常并不能有效地调制大气环流. 直至5月份，其对周边 大气环流异常的强迫逐渐占据主导, 并可以持续到6月 份. 5 6月TWI地区的异常增暖可以通过调制季风区经 圈环流, 有效地影响WNPAC, 致使其西北侧的西南风 为长江流域输送源源不断的水汽, 为强降水过程的发 生提供有利条件. CAM5模式的试验结果进一步证实 了前期TWI地区暖海温异常对长江流域水汽条件的有 利影响.

21世纪初期之后, TWI地区 5 月份异常海温经历了 由冷位相到暖位相的年代际转换. 区域平均的 TWII指 数显示, 2020 年 5 月的量值超过了 $0.7^{\circ} \mathrm{C}$, 达 1.8 倍标准 差. 由此可见, 2020 年5月TWI地区海温的年代际增暖, 极有可能通过影响WNPAC, 增加2020年梅雨期内长江 流域强降水的发生概率.

本文重点探讨了热带海洋的年代际增暖对6月长 江流域降水的影响, 但是2020年7月长江流域遭受了多 次超强持续性降水过程的侵袭. 年代际尺度上其他因 子对7月极强梅雨降水有何贡献仍然未知. 丝绸之路 遥相关、太平洋-日本遥相关等具有显著年代际振荡 的中纬度环流系统也可以显著调节东亚夏季气候 (Chowdary等, 2019; Li等, 2019; Xu等, 2019), 它们对 2020年超强梅雨的贡献如何? 仍需要更深入的研究予 以解答.
本文利用谐波分解来分离2020年6 7月长江流域 降水和相应大气环流的年代际分量, 这一方法所带来 的首尾误差不可忽视. 为初步讨论首尾误差可能造成 的影响，将研究时段从1979 2015年逐年滑动至 1979 2020年，对比分析不同研究时段6月YRVRI指数 年代际分量的差异. 如图13a所示，尾端年份不同，所 分离出的年代际分量虽然存在差异, 但是6月长江流域 降水均呈现出年代际增多的特征. 由此可见, 2020年超 强梅雨的出现的确可以部分归因于年代际降水的增 多. 虽然首尾误差的存在部分限制了本文对于年代际
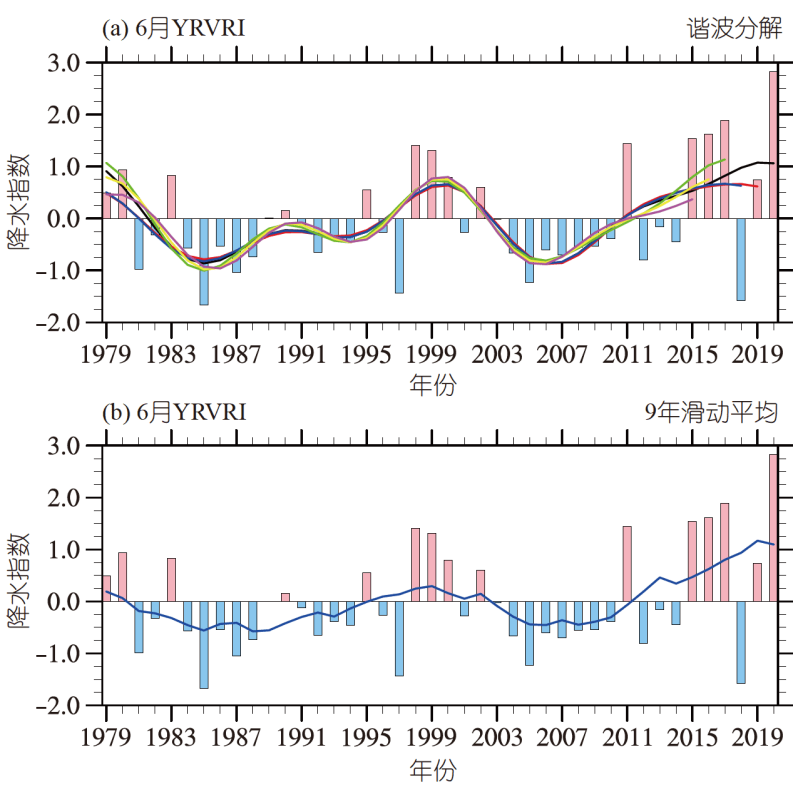

图 13 1979 2020年6月YRVRI指数(柱状图)和利用不同滤 波方法所得的年代际分量(实线)

(a) 不同尾端年份的谐波分解; (b) 9 年滑动平均 
因子的定量诊断, 但是并不影响针对TWI地区年代际 增暖影响超强梅雨的定性结果.

此外, 本文还进一步对比分析了谐波分解和 9 年滑 动平均这两种年代际分量提取方法的差异. 计算 9 年滑 动平均时, 1983 2016年采用常规的9年滑动窗口, 其余 的首尾年份则依次缩小滑动窗口. 例如, 2017年采用8 年滑动窗口(即2013 2020年平均), 2018年采用7年滑 动窗口(即2014 2020年平均), 以此类推分别计算首尾 年份的年代际分量. 采用9年滑动平均后，2020年6月 YRVRI指数的年代际分量约为 1.10 个标准差, 而采用 谐波分解所得值约为 1.06 个标准差, 滤波结果相近, 表 明2020年长江流域降水的年代际分量对滤波方法并不 敏感.

\section{参考文献}

符淙斌, 滕星林. 1988. 我国夏季的气候异常与埃尔尼诺 / 南方涛动 现象的关系. 大气科学, 12: 133-141

梁萍, 陈丽娟, 丁一汇, 何金海, 周兵. 2018. 长江梅雨的长期变率与 海洋的关系及其可预报性研究. 气象学报, 76: 379-393

梁萍, 丁一汇. 2012. 东亚梅雨季节内振荡的气候特征. 气象学报, 70: $418-435$

潘旸, 沈艳, 宇婧婧, 熊安元. 2015. 基于贝叶斯融合方法的高分辨率 地面-卫星-雷达三源降水融合试验. 气象学报, 73: 177-186

魏风英, 谢宇. 2005. 近百年长江中下游梅雨的年际及年代际振荡. 应用气象学报, 16: 492-499

杨静, 钱永甫. 2009. 121a梅雨序列及其时变特征分析. 气象科学, 29: $285-290$

Chang C P, Zhang Y, Li T. 2000. Interannual and interdecadal variations of the East Asian summer monsoon and tropical Pacific SSTs. Part I: Roles of the subtropical ridge. J Clim, 13: 4310-4325

Chen J, Wang X, Zhou W, Wang C, Xie Q, Li G, Chen S. 2018. Unusual rainfall in Southern China in decaying august during extreme El Niño 2015/16: Role of the Western Indian Ocean and north tropical Atlantic SST. J Clim, 31: 7019-7034

Chen W, Feng J, Wu R. 2013. Roles of ENSO and PDO in the link of the East Asian winter monsoon to the following summer monsoon. J Clim, 26: 622-635

Chen W, Wang L, Feng J, Wen Z, Ma T, Yang X, Wang C. 2019. Recent progress in studies of the variabilities and mechanisms of the East Asian monsoon in a changing climate. Adv Atmos Sci, 36: 887-901

Chowdary J S, Hu K, Srinivas G, Kosaka Y, Wang L, Rao K K. 2019. The Eurasian jet streams as conduits for East Asian monsoon variability. Curr Clim Change Rep, 5: 233-244
Ding R, Ha K J, Li J. 2010. Interdecadal shift in the relationship between the East Asian summer monsoon and the tropical Indian Ocean. Clim Dyn, 34: 1059-1071

Ding Y, Liang P, Liu Y, Zhang Y. 2020. Multiscale variability of Meiyu and its prediction: A new Review. J Geophys Res Atmos, 125: e31496

Feng J, Wang L, Chen W. 2014. How does the East Asian Summer monsoon behave in the decaying phase of El Niño during different PDO phases? J Clim, 27: 2682-2698

Ge Q S, Guo X F, Zheng J Y, Hao Z X. 2008. Meiyu in the middle and lower reaches of the Yangtze River since 1736. Chin Sci Bull, 53: $107-114$

Ha Y, Zhong Z, Chen H, Hu Y. 2016. Out-of-phase decadal changes in boreal summer rainfall between Yellow-Huaihe River Valley and southern China around 2002/2003. Clim Dyn, 47: 137-158

Huang B, Thorne P W, Banzon V F, Boyer T, Chepurin G, Lawrimore J H, Menne M J, Smith T M, Vose R S, Zhang H M. 2017. Extended reconstructed sea surface temperature, Version 5 (ERSSTv5): Upgrades, validations, and intercomparisons. J Clim, 30: 8179-8205

Huang R, Chen J, Wang L, Lin Z. 2012. Characteristics, processes, and causes of the spatio-temporal variabilities of the East Asian monsoon system. Adv Atmos Sci, 29: 910-942

Kanamitsu M, Ebisuzaki W, Woollen J, Yang S K, Hnilo J J, Fiorino M, Potter G L. 2002. NCEP-DOE AMIP-II reanalysis (R-2). Bull Amer Meteor Soc, 83: 1631-1644

Lau K M, Lee J Y, Kim K M, Kang I S. 2004. The North Pacific as a regulator of summertime climate over Eurasia and North America. J Clim, 17: 819-833

Li J, Zheng F, Sun C, Feng J, Wang J. 2019. Pathways of influence of the northern hemisphere mid-high latitudes on East Asian climate: A review. Adv Atmos Sci, 36: 902-921

Li T, Wang B, Wu B, Zhou T, Chang C P, Zhang R. 2017. Theories on formation of an anomalous anticyclone in Western North Pacific during El Niño: A review. J Meteorol Res, 31: 987-1006

Liu B, Yan Y, Zhu C, Ma S, Li J. 2020. Record-breaking Meiyu rainfall around Yangtze River in 2020 regulated by the subseasonal phase transition of North Atlantic Oscillation. Geophys Res Lett, 47: e90342

Liu Y, Chang J C H. 2012. Coordinated abrupt weakening of the Eurasian and North African monsoons in the 1960s and links to extratropical North Atlantic cooling. J Clim, 25: 3532-3548

Mantua N J, Hare S R. 2002. The Pacific decadal oscillation. J Oceanography, 58: 35-44

Mantua N J, Hare S R, Zhang Y, Wallace J M, Francis R C. 1997. A Pacific interdecadal climate oscillation with impacts on salmon production. Bull Amer Meteor Soc, 78: 1069-1079 
Neale R B, Gettelman A, Lauritzen P H, Park S, Williamson D, Conley A, Garcia R, Kinnison D, Lamarque J, Marsh D, Mills M, Smith A, Tilmes S, Vitt F, Morrison H, Cameron-Smith P, Collins W, Iacono M J, Easter R, Ghan S, Liu X, Rasch P, Taylor M. 2012. Description of the NCAR Community Atmosphere Model (CAM 5.0). NCAR Tech Note NCAR/TN-486+STR, 289

Saji N H, Goswami B N, Vinayachandran P N, Yamagata T. 1999. A dipole mode in the Tropical Indian Ocean. Nature, 401: 360-363

Schlesinger M E, Ramankutty N. 1994. An oscillation in the global climate system of period 65-70 years. Nature, 367: 723-726

Si D, Ding Y. 2016. Oceanic forcings of the interdecadal variability in east Asian summer rainfall. J Clim, 29: 7633-7649

Si D, Ding Y H, Liu Y J. 2009. Decadal northward shift of the Meiyu belt and the possible cause. Sci Bull, 54: 4742-4748

Sun B, Wang H, Zhou B, Li H. 2019. Interdecadal variation in the synoptic features of Mei-Yu in the Yangtze river valley region and relationship with the pacific decadal oscillation. J Clim, 32: 62516270

Wang B, LinHo B. 2002. Rainy season of the Asian-Pacific summer monsoon. J Clim, 15: 386-398

Wang B, Wu R, Fu X. 2000. Pacific-East Asian teleconnection: How does ENSO affect East Asian climate? J Clim, 13: 1517-1536

Wang B, Wu R, Lau K M. 2001. Interannual variability of the Asian summer monsoon: Contrasts between the Indian and the Western North Pacific-East Asian monsoons. J Clim, 14: 4073-4090

Watanabe M, Jin F. 2002. Role of Indian Ocean warming in the development of Philippine Sea anticyclone during ENSO. Geophys Res Lett, 29: 116-1-116-4

Wu B, Li T, Zhou T. 2010. Relative contributions of the Indian Ocean and local SST anomalies to the maintenance of the western North pacific anomalous anticyclone during the El Niño decaying summer.
J Clim, 23: 2974-2986

Wu B, Zhou T, Li T. 2009. Seasonally evolving dominant interannual variability modes of East Asian climate. J Clim, 22: 2992-3005

Xie M, Wang C. 2020. Decadal variability of the anticyclone in the Western North Pacific. J Clim, 33: 9031-9043

Xie P, Yatagai A, Chen M, Hayasaka T, Fukushima Y, Liu C, Yang S. 2007. A gauge-based analysis of daily precipitation over East Asia. J Hydrometeorol, 8: 607-626

Xie S P, Hu K, Hafner J, Tokinaga H, Du Y, Huang G, Sampe T. 2009. Indian Ocean capacitor effect on Indo-Western pacific climate during the summer following El Niño. J Clim, 22: 730-747

Xie X, Wang H, Liu X, Li J, Wang Z, Liu Y. 2016. Distinct effects of anthropogenic aerosols on the East Asian summer monsoon between multidecadal strong and weak monsoon stages. J Geophys Res Atmos, 121: 7026-7040

Xu P, Wang L, Chen W, Feng J, Liu Y. 2019. Structural changes in the Pacific-Japan pattern in the late 1990s. J Clim, 32: 607-621

Zhang Y, Wallace J M, Battisti D S. 1997. ENSO-like interdecadal variability: 1900-93. J Clim, 10: 1004-1020

Zhang H, Wen Z, Wu R, Chen Z, Guo Y. 2017. Inter-decadal changes in the East Asian summer monsoon and associations with sea surface temperature anomaly in the South Indian Ocean. Clim Dyn, 48: 1125-1139

Zhang R, Sumi A, Kimoto M. 1996. Impact of El Niño on the East Asian monsoon. J Meteorol Soc Jpn, 74: 49-62

Zhu Y, Wang H, Ma J, Wang T, Sun J. 2015. Contribution of the phase transition of Pacific Decadal Oscillation to the late 1990s' shift in East China summer rainfall. J Geophys Res Atmos, 120: 8817-8827

Zhu Z, Li T, He J. 2014. Out-of-Phase relationship between boreal spring and summer decadal rainfall changes in southern China. J Clim, 27: 1083-1099 